\title{
The free/open source software movement Resistance or change?
}

\author{
O movimento de software livre/aberto
}

Resistência ou mudança?

Panayiota Georgopoulou*

\begin{abstract}
At a time when private companies are inventing methods of "locking information" and when neo-liberal governments are imposing strict sanctions on those who violate intellectual property rights, the Free/Open Source Software (FOSS) movement has been countering neo-liberalism and general privatization: it defies ownership regulations in a key area of growth in contemporary capitalistic societies, namely, the construction and use of information. At the end of the ' 90 s, FOSS seemed to be a disruptive and destabilizing force in terms of intellectual property and neoliberalism, yet as open software, it has evolved into a singular economic phenomenon indicating that commercialization and financial gain can now exist without being based on the notion of ownership. This may not be detrimental to capitalistic logic, but broaden its prospects. By negating the ownership regime imposed on information and putting the historical potential of the "economy of abundance" of the new digital world to good use, is FOSS then laying down a plan for political resistance or showing the way towards a potential transformation of capitalism? Perhaps the new conditions of politics can be found in the heart of economy and in its transition towards an "economy of abundance" in the digital world.
\end{abstract}

Keywords: Copyright; Free information; Community; Free/Open Source Software; Economy of abundance

Resumo: Num momento em que as empresas privadas estão inventando modos de "bloqueio de informação" e em que governos neo-liberais estão impondo sanções severas para aqueles que violam os direitos de propriedade intelectual, o Movimento de Software Livre/Aberto foi contra o neo-liberalismo e a privatização generalizada: o movimento desafia regulações de propriedade em uma área-chave de crescimento das sociedades capitalistas contemporâneas, a saber, a construção e utilização de informações. No final dos anos 1990, o Movimento de Software Livre/Aberto parecia ser uma força desestabilizadora e perturbadora da propriedade intelectual e do neo-liberalismo, ainda como software aberto, ele se transformou em um fenômeno econômico singular, indicando que a comercialização e ganhos financeiros já podem existir sem que se baseie no conceito de propriedade. Isto pode não ser prejudicial para

* Lecturer, Panteion University, Greece; e-mail: pgeorgop@panteion.gr

\begin{tabular}{|l|l|l|l|l|l|}
\hline Civitas & Porto Alegre & v. 9 & n. 1 & p. $65-76$ & jan.-abr. 2009 \\
\hline
\end{tabular}


a lógica capitalista, mas alargar as suas perspectivas. Ao negar o regime de propriedade imposto sobre a informação e ao colocar o potencial da "economia de abundância" do novo mundo digital à disposição da boa utilização, o Movimento de Software Livre/ Aberto está desistindo de um plano de resistência política ou mostrando o caminho para uma potencial transformação do capitalismo? Talvez as novas condições da política podem ser encontradas no coração da economia e na sua transição em direção a uma "economia de abundância" no mundo digital.

Palavras-chave: Direito de propriedade; Liberdade de informação; Software Livre/Aberto, Economia de abundância

Free/Open Source Software (FOSS) is an alternative model of software development and distribution that is founded on principles of free exchange of information and open collaboration. In contrast to the commercial, proprietary software that is sold as a commodity, this software is free to be copied and distributed. For example, one can go on-line and download it from official Internet sites at minimal or no cost. And unlike the commercial software products, the source code, the script written by engineers and developers in programming languages, is not hidden, black-boxed or private, but is free to be read, modified and re-distributed. Therefore, giving away and sharing source codes promote collaborative social relations that are not regulated by the possession or exchange of money or commodities, but are based on gift-giving practices (Mauss, 1950/1999) in the on-line world. So, you write a piece of software and make it available to the community. FOSS has been enormously successful on the Internet. In fact, much of the underlying technology of the Internet has been developed using free/open source software, such as networking infrastructure, web servers and browsers. In this respect, the success and the widespread growth of this model of freely sharing information and keeping the source code of FOSS open have been discussed not simply in technical terms, but as a politics, a critique, a social movement, a revolution or even a "way of life" (Kelty, 2004).

At a time when information is treated as a commodity - books, music, films, games, software are sold as such - and when governments are imposing strict sanctions on those who violate intellectual property rights, the practices of FOSS seem to be going in the opposite direction: they defy intellectual property laws and regulations, challenge privatization and support community activities and values in a key area of growth in contemporary capitalistic societies, namely, the construction and use of digital information (Castells, 1989). My argument here is that in the age of transition from the industrial to the Information Age (Castells, 1996), this model of free exchange and open 
collaboration via FOSS constitutes a political intervention in our society: we are at pivotal point concerning the political struggle between contesting political visions and interests over the digital world's future. To understand the logic of the political intervention of the FOSS movement, I will focus on two questions. Firstly, where does the political significance of this FOSS model stem from? Secondly, what kinds of politics are inscribed in FOSS practices? For our purposes, it will be instructive to refer to one of the most famous Free/Open Source Software called GNU/Linux operating system, initiated by Richard Stallman and Linus Torvalds respectively.

\section{The historical development of GNU/Linux}

In the early 1980s, as a member of a group of programmers/researchers in the Artificial Intelligence Laboratory at MIT (AI Lab) - one of the most important hacker communities ${ }^{1}$ - Richard Stallman decided to go against (Williams, 2002) the attempt of software companies to privatize the outcomes of their research. What's significant here is the manner in which he legally protected the GNU project (the initials stand for GNU Not Unix) and under whose legal framework Linux was brought in the 1990s.

Continuing the tradition of considering knowledge a common good and advocating its free circulation, Stallman supported that software, like any other form of knowledge, constitutes a collective/common good that should be freely shared by all humanity. ${ }^{2} \mathrm{He}$ thus decided to secure the legal rights of his project in an unusual manner. With the help of a legal consultant, he composed what is called the "General Public License (GPL) for GNU. Any software published under the legal license to use GPL Stallman named "free software". While protecting the intellectual rights of the software author, this license denies him or her the right to ownership. In this way, GPL protects the user from any technical or legal restrictions in using, distributing and modifying the software. This also means that the programmers do not have any rights to ownership of any modifications or improvements they may make on the already existing free product. On the contrary, they are obliged to submit the product to the "free regime" of free software.

1 These communities sought not only to create computer programs but also to improve them. These improvements were called hacks and their members hackers. One of the most representative ones was MIT's Al Lab, where Richard Stallman, an exemplary hacker, started his struggle for the free use and distribution of software.

2 See the official site of the Free Software Foundation GNU Project. R. Stallman, Freedom or Copyright? (consulted November 2006) http//:gnu.org/philosophy/freedom-or-copyright.html

3 See the official site of the Free Software Foundation GNU Project. URL (consulted December 2008): www.gnu.org/licences/translations.html 
In addition, the "General Public License" (GNU GPL) becomes even more interesting under the following condition: it obliges anyone using a part of the code published under the GPL license in his or her own program to submit the whole program to the GPL, even if other parts of the program fall under laws regarding intellectual rights. This means on the whole that from the moment that GNU/Linux, as free/open software, is combined with private software, it "infects" (Ceruzzi, 2006, p. 381) the proprietary regime and the "closed" nature of the latter, transforming it into "free" software. As opposed to what occurred in the software industry, where the advance of capitalist logic imposed the privatization of knowledge and information, the distribution and use of GNU/Linux under GPL has proved to this day to be particularly "dangerous": the aggressor here has switched sides and instead of free software becoming privatized, it, in fact, turns against the world of capitalist software production companies, incorporating the latter's products in the rationale of free software.

Given this hard-line policy, Stallman, along with other supporters, founded a non-profit organization in 1983 called Free Software Foundation (FSF), which undertook the promotion of free software, independent of GNU and the GPL. From the very start, this organization broadened the terms ${ }^{4}-$ beyond the specific GPL license - according to which a program could acquire a free software license. These terms focus on the software users and not the author, allowing them the freedom to redistribute, modify or improve the software, and became known as a legal system called copyleft, as opposed to copyright, which promotes the rationale of privatizing knowledge or information, alluding to a conservative political outlook (right-wing), with copyleft, Stallman reverses the rationale regarding intellectual rights to the benefit of the common good: ${ }^{5}$ instead of the software author or producer being legally protected, it is the rights and liberties of the user that are safeguarded (Wark, 2004, p. [070]). Information now belongs to everyone. In this way, the principle of the availability and free distribution of knowledge or information acquires legal and real validity; it

\footnotetext{
4 A program is free software if users are free to do all of the following:

- run the program, for any purpose (freedom 0 ).

- study how the program works, and adapt it to your needs (freedom 1). Access to the source code is a precondition for this.

- redistribute copies so you can help your neighbour (freedom 2).

- improve the program, and release your improvements to the public, so that the whole community benefits (freedom 3). Access to the source code is a precondition for this.

See the official site of Free Software Foundation for the text The free software definition, URL (consulted December 2008) http://www.gnu.org/philosophy/free-sw.html

5 Stallman typically paraphrases "Copyright - All rights reserved" as "Copyleft - All rights reversed".
} 
becomes social practice through the use of free software and does not remain at a mere utopian declaration.

Taking advantage of the potential of the Internet, in the early ' $90 \mathrm{~s}$, a 22-year-old Finnish programmer named Linus Torvalds created the Linux program by means of collective teamwork. After writing the initial version of Linux, he made his program freely available through the Internet without any financial or technical restrictions and urged users to contribute to its improvement and development. There was an immediate response to this call and over the course of the decade Linux was developed and enhanced by enthusiastic and dedicated groups of volunteer programmer/users all over the world.

Thus, a program, which does not necessarily operate effectively, is distributed and users are called upon to participate in its development. Now having free access to the Linux source code, the users are transformed from simple consumers into co-producers of the program, pinpointing the problems and sometimes correcting them or adding new functions. In this way, the free access to the source code allows for a decentralized and collective method of developing software that is not directly dictated by criteria concerning its potential financial returns, but is based on the participants taking personal pleasure in creating, openly collaborating and enjoying the team spirit (Raymond, 1999).

The GNU and Linux programs are closely related. When Torvalds started writing Linux, he based his work on Stallman's and on GNU software tools. From a technical standpoint, Stallman's contribution was so significant in the creation of Linux that Stallman never ceases to point out that Linux should be called GNU/Linux. Torvalds, in turn, was the one who placed Linux under the legal protection of GNU GPL, something which defined its special and radical nature in comparison to private companies' closed operating systems, which are legally bound by intellectual property rights. Since then Linux has not stopped being enhanced with new functions and applications added by thousands of anonymous user/programmers, who are connected through cyberspace and labour creatively with no direct view to financial gains.

The decentralized and collective organization of production (Raymond: 1999), which encourages collaborative solidarity and the willingness to give and which became possible via the free/open access to the software source code, makes Linux not only a successful technological achievement, but also a significant social phenomenon. What renders it particularly interesting is not only the promotion of a division of labour that overturns a centralized organization of production, but also the fact the mobilization and participation 
of the programmers worldwide has been motivated by the revival of gift-giving practices and not direct financial profit.

These two significant initiatives taken by Stallman and Torvalds, in tandem with the communication possibilities of the Internet and the mobilization of thousands of supporters worldwide, shaped the profile of GNU/Linux as an open source/free software and set the example for an alternative approach to producing and distributing knowledge. The remarkable thing here is that the product of this alternative approach - GNU/Linux - has become a threat to Microsoft's monopoly (Kerstetter et al., 2003, p. 78-84).

\section{The political significance of the FOSS Model: the "economy of abundance"}

What, however, are the reasons for the success of this model of free exchange of information and open collaboration? And where does the political significance of this FOSS model stem from? In my view, the real conditions of FOSS alternative methods can be found in the "economy of abundance", a state that is an integral part of the production of information or knowledge. In contrast to the principles of the classic economy of the scarcity of material goods, where the material goods are limited and run out, when I give information away, I don't lose it and if I use it, I don't destroy it (Lévy, 1999, p. 73, Goldfinger, 1994). By definition, information is incessantly reproductive and infinite. Therefore, if the scarcity of material goods creates an economy of scarcity, the infinite nature of information creates an economy of abundance.

In an economy of abundance that shapes information, the scarcity or lack of information imposed by the intellectual property regime is entirely artificial. If we can share information without losing it, the restrictions on access, use and circulation imposed by privatization are no longer legally sound and become provocatively artificial. For Stallman, the monopoly on information enjoyed by software companies creates an artificial scarcity that is unethical (Williams, 2002). Specifically, in his text, Freedom or Copyright?, he claims that the world has changed with digital technology. The new mode of distributing information allows for the limitless and easy copying and processing of all types of information and at the same time, the networked organization offers limitless access to all types of information. The economy of abundance offered by the digital world renders the sharing and free dissemination of knowledge as objective, natural and beneficial activities. In this way, the abolition of the principle of intellectual property obeys the "natural" commands of the new digital conditions and tenaciously hanging onto the proprietary model 
has become out-dated and reactionary, depriving the individual and society as a whole of the benefits of computer technology. In this respect, instead of publishers, companies and governments following the natural demands of the times, they artificially impose the intellectual property regime and penalize the natural and socially beneficial practice of freely sharing information. For Stallman, the widespread use of digital technology by citizens will unavoidably create the need to resist this now artificial (and not "natural") intellectual property regime. As he notes in the above-mentioned work, "Humanity will not accept this yoke forever." The potential vehicle of revolutionary change is now the very use of digital technology. ${ }^{6}$

Moreover, the imposition of the proprietary model in this field stifles creativity and the innovative character of information. Contrary to the economy of scarcity of material goods, the use of information cannot be taken as the destruction or loss of ideas, but as a gift of thoughts, whose free circulation ensures the creative use of information. In other words, consumption is productive (Lévy, 1999, p. 90-91). Using it activates an act of interpretation, combining it with other knowledge and data or inventive solutions to problems. Every time this happens, it is a small creation (Lévy, 1999, p. 77).

After all, the scientific community has long been functioning under the conditions of the economy of abundance. Research results are published in scientific journals, reviews and conferences, thus assisting the free dissemination and circulation of knowledge, which has been proven to be the most efficient method of advancing knowledge (Hagstrom, 1982). In the same way, the free and open character of software development plays a decisive role in advancing the science of software. As Raymond notes, "Given enough eyeballs, all bugs are shallow" (1999). The locking of information that the proprietary regime wants to impose goes against the improvement of software quality, essentially sacrificing the possibilities for creating or advancing knowledge. In other words, we find ourselves before a scarcity of innovation.

Finally, since the use of knowledge does not create phenomena of deprivation or destruction, but instead promotes the creation of new knowledge, social bonds and collaborations are created based on mutual interests and needs. Desiring to broaden their horizons or solve specific problems, the information

6 From this point of view, the economy of scarcity that is produced by the intellectual proprietary regime cannot compete with the abundance of the gift, which digital technology includes as a potential condition (Barbrook, 2000, p. 21). Indeed, as it has become apparent from Internet users, this practise speaks for a utopia of common free information, where information is shared without one being deprived of it. As R. Barbrook (2000, p. 25) tellingly mentions, regardless of Internet users' political ideologies, they can participate in the activation of a cyber-communism, seeking the digital overthrow of capitalism. 
users can freely participate in the dissemination, processing and modification of information; essentially, they have nothing to lose and only knowledge to gain. This possibility of gain without loss promotes the free exchange of "knowledge gifts" and creates peer networks, encouraging a collaborative mentality, sharing and solidarity amongst the participants.

The possibilities, therefore, of transcending intellectual property and well as the emergence of a gift-giving culture can be found in the digital world's economy of abundance. Where the proprietary model insists on not taking advantage of the potentialities of the economy of abundance, FOSS has proceeded to make them a reality. Contrary, therefore, to the policy of Microsoft or many other software firms and governments which insist on subjecting information to proprietary schemes, FOSS takes advantage of the historic potentialities - and not the necessities - of the new digital world, creating a scheme of political intervention. In other words, the political significance of the FOSS model can be found in activating the possibilities of the "economy of abundance".

\section{What kinds of politics are inscribed in FOSS practices?}

If the politics are rooted in the activation of the economy of abundance, what kinds of politics are inscribed in practices of Free/Open Source Software? Regarded as political intervention, the model of free information and open, self-organized collaboration of FOSS indicates two plausible political alternatives for the future of the Information Áge: a politics of resistance and a politics of change or transformation of capitalism. Indeed, in the late 90's, after the remarkable boom in the number of FOSS users and developers, a conflict broke out between the "Free Software" radical politics represented by Stallman and the "Open Source Approach" as an alternative business model for the economic development of digital capitalism. In fact, in 1998, the Open Source Initiative (OSI) non-profit organization was founded with the aim of promoting "open source" software.

As a politics of resistance, for Stallman and the Free Software Foundation (FSF) free information involves a democratic politics of promoting individual freedom and community solidarity at the same time. While emphasizing the political value of the free access to information, Stallman does not fail to point out that the concept of the freedom of information should be understood in the same way one understands freedom of speech, that is, as a cultural and social value and one should not take it as having to do merely with economics or technology. Stallman (1999) notes, "The GNU Project continues to use the 
term 'free software' to express the idea that freedom, not just technology, is important."

More specifically, the freedom of information can be equated with the freedom of speech and individual expression, that is, "free" as in "free speech" and not as in "free beer" (Stallman, "Free Software Definition"). As in the context of liberal political thought, censorship and excessive interventions by the powers-that-be silence free speech and free expression. This results in impoverishing individuality both intellectually and ethically, limiting the range of options and lifestyles. In the same way, monopolizing information by means of the proprietary regime deprives the individual of creativity, pleasure and satisfaction; it limits the range of options and adopts the form of passive compliance, leading to the smothering of free thought and expression. Fencing information within the boundaries of ownership is what poses a threat to individual freedom and self-realization. From this viewpoint, copyleft ratifies the conditions that will allow freedom of speech and personal expression.

In addition, free information reinforces the community model as a democratic alternative for the development of our society. Influenced by the liberalist, leftist leanings of the hippies in the late ' $60 \mathrm{~s}$, for Stallman, free information is a political issue because it strengthens the bond between individual freedom and a self-regulated and collaborative society that rules out and considers the concentration of power and social control in the hands of the few as hostile. In contrast, the proprietary regime deprives society of the potential of re-establishing social bonds based on solidarity and mutual collaboration. More specifically, Stallman (1999) writes, "Computer users should be free to modify programs to fit their needs, and free to share software, because helping other people is the basis of society." He also concedes that he could have done nothing and just remained a mere programmer. "[But] I knew that at the end of my career I would look back on years of building walls to divide people and feel I had spent my life making the world a worse place."

As a politics of change, Open Source Software points the way towards a potential transformation of capitalism. For the supporters of open software, the principle of free or open information is a more effective method of developing innovations and improving the quality of programs in the face of the conventional software industry (Perens, 2005). "The locking of ideas" imposed by privately-owned software companies goes against improving the quality of programs. Locking knowledge or information through ownership essentially deprives one of the potential to create new knowledge or improve the quality of existing programs. In the context of the economy of abundance of information, the principle of free information and the open source business 
mentality of extroversion and collaboration serves quality itself and innovation in the construction of software (Raymond, 1999). In this way, the market demands and the overall efficiency of the economy are served in the best way. Contrary to the industrial age, a new logic emerges in the Information Age: undermining the principle of ownership in the field of information is not connected to the de-stabilization of the capitalist market as one might simplistically surmise. It is, in fact, an unconventional means of promoting a rationale of development (Mackenzie, 2001). In the same way, the revitalization of a collaborative mentality and the gift-giving process does not contest profitmaking logic; instead, it can become a significant means for promoting it. Today, web communities have become big business.

In this strain, the supporters of open sources software endeavour to change the rules of the IT industry, seeking to win over the software market. Thus, at the end of the ' 90 s, open source software became a singular economic phenomenon suggesting that commercialization and economic profit can exist without the proprietary regime. More specifically, while the software itself is free and can be freely downloaded from the corresponding websites, the support and maintenance services as well as the distribution of informational material on the use and installation of the program are not free or openly accessible. This outlines a new field of commercial exploitation that generates great profits. Open source software companies, such as Redhat, VALinux Systems and Mandrake are involved in this sort of economic activity and, in fact, pay hackers to develop their software, which they subsequently make freely available. In addition, major companies such as IBM, Apple, Sun and Oracle, which in the past clung to operating systems that were locked and bound by intellectual property rights, are now not only incorporating open source software in their products but are also providing some of their own software products as open source software. A resounding exception in this change of course in large-scale software companies is Microsoft, which continues to publicly renounce the phenomenon of free/open source software.

In this context, the political question arises: Should the emerging information capitalism be built in the image of the old industrial capitalist economy? Or should it be built on the alternative business model of commodity/ gift hybrids? In the first case, intellectual property regimes are retained, thus perpetuating the existing social order. Of course, this may endanger the development of capitalism. In the second case, with the practice of gift-giving as a new business model, existing social order is very possibly destabilized, but the development of capitalism is preserved. 


\section{Conclusion}

By refusing to regard information as private property, FOSS takes advantage of and puts into practice the historic potentialities of economy of abundance. From this non-deterministic standpoint, FOSS makes a political intervention in our society, in which information is the key area of growth. With regard to the digital world's future, which is not fixed or deterministic, we are at pivotal point concerning the political struggle between the dominant and powerful commercial interests that advocate privatization and commercialization on the one hand, and the FOSS movement that supports a plan for political resistance or showing the way towards a potential transformation of capitalism on the other hand. Perhaps the new conditions of politics can be found in the heart of economy and in its transition towards an economy of abundance in the digital world.

\section{References}

BARBROOK, Richard. Cyber-communism: how the Americans are superseding capitalism in cyberspace. Science as Culture. v. 9, n. 1, p. 5-40, 2000

CASTELLS, Manuel. The information city, Oxford: Basil Blackwell, 1989.

. The information age: economy, society and culture. v. 1: The rise of the network society. Malden and Oxford: Blackwell Publishers, 1996.

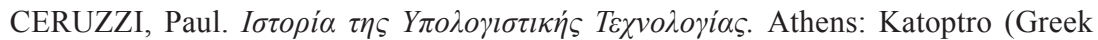
translation), 2006. In the original, A history of modern computing ( $2^{\text {nd }}$ edition), Massachusetts Institute of Technology, 2003.

GOLDFINGER, Charles. L'utile et le futile: l'économie de l'immatériel. Paris: Odile Jacob, 1994.

Free Software Foundation GNU Project. Licenses, URL (consulted December 2008): www.gnu.org/licences/translations.html_

Free Software Foundation GNU Project. The Free Software Definition, URL (consulted December 2008) http://www.gnu.org/philosophy/free-sw.html

HAGSTROM, Warren. Gift-giving as an organizing principle in science. Science in Context. Barnes, B. \& Edge, D. (eds.). Stony Stanford: The Open University Press, 1982.

KELTY, Christofer. Culture's open sources: software, copyright and cultural critique. Anthropological Quarterly, v.77, n. 3, p. 499-506, 2004.

KERSTETTER, Jim et al. The Linux uprising. Business Week, 3 Mar, p. 78-84, 2003.

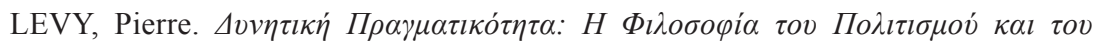

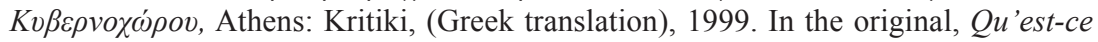
que le virtuel? Paris: Editions La Découverte, 1995. 
MACKENZIE, Adrian. Open source software: when is it a tool? What is a commodity? Science as Culture, v. 10, n. 4, p. 541-552, 2001.

MAUSS, Marcel. The gift: the form and reason for exchange in archaic societies. London: Routedge, 1950/1999.

PERENS, Bruce. The emerging economic paradigm of open source. First Monday's Special Issue 2 Open Source: October 2005. URL (consulted December 2008), http:// firstmonday.org/htbin/cgiwrap/bin/ojs/index.php/fm/article/view/1470/1385

RAYMOND, Eric. The cathedral and the bazaar: musings on Linux and open source by an accidental revolutionary. Sebastopol: O'Reilly and Associates, 1999. URL (consulted December 2008) www.catb.org/ esr/writings/cathedral-bazaar

STALLMAN, Richard. The GNU operating system and the Free Software Movement. Open sources: voices from the open source revolution, 1. ed. Jan. 1999. URL (consulted December 2008) www.oreilly.com/catalog/opensources/book/toc.html

Freedom or Copyright? URL (consulted November 2006) www.gnu.org/ philosophy/freedom-or-copyright.html

WARK, McKenzie. A hacker manifesto. President and fellows of Harvard College, 2004.

WILLIAMS, Sam. Free as in freedom: Richard Stallman's crusade for free software. Sebastopol: O'Reilly, 2002. URL (consulted November 2008): www.oreilly.com/ openbook/freedom 